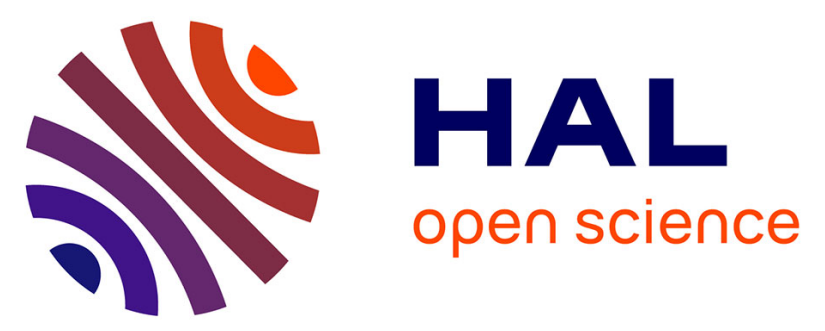

\title{
Automatically optimized near-field focusing radial line slot array
}

\author{
Mauro Ettorre, Massimiliano Casaletti, Guido Valerio, Ronan Sauleau, \\ Laurent Le Coq, Santi Concetto Pavone, Matteo Albani
}

\section{- To cite this version:}

Mauro Ettorre, Massimiliano Casaletti, Guido Valerio, Ronan Sauleau, Laurent Le Coq, et al.. Automatically optimized near-field focusing radial line slot array. Conference APSURSI 2014, Jul 2014, Memphis, United States. pp.1049 - 1050, 10.1109/APS.2014.6904851 . hal-01071525

\section{HAL Id: hal-01071525 \\ https://hal.sorbonne-universite.fr/hal-01071525}

Submitted on 6 Nov 2014

HAL is a multi-disciplinary open access archive for the deposit and dissemination of scientific research documents, whether they are published or not. The documents may come from teaching and research institutions in France or abroad, or from public or private research centers.
L'archive ouverte pluridisciplinaire HAL, est destinée au dépôt et à la diffusion de documents scientifiques de niveau recherche, publiés ou non, émanant des établissements d'enseignement et de recherche français ou étrangers, des laboratoires publics ou privés. 


\title{
Automatically Optimized Near-Field Focusing Radial Line Slot Array
}

\author{
Mauro Ettorre*, Massimiliano Casaletti ${ }^{\dagger}$, Guido Valerio*, Ronan Sauleau*, Laurent Le Coq*, \\ Santi C. Pavone ${ }^{\ddagger}$ and Matteo Albani ${ }^{\ddagger}$ \\ ${ }^{*}$ Institut d'Electronique et de Télécommunications de Rennes (IETR) \\ UMR CNRS 6164, Université de Rennes 1, 35042 Rennes Cedex, France \\ ${ }^{\dagger}$ Laboratoire d'Electronique et Electromagnétisme (L2E), Pierre and Marie Curie University - Paris 6, 75005 Paris, France \\ ${ }^{\ddagger}$ Dipartimento di Ingegneria dell’Informazione, Universitá degli Studi di Siena, Via Roma 56, 53100, Siena, Italy
}

\begin{abstract}
We present an automatically optimized near-field focusing radial line slot array (RLSA) antenna. The side lobe level and beamwidth of the normal component of the radiated electric field are controlled during the design process. A set theoretic approach is used to derive the RLSA aperture field distribution generating the required near field over a focusing plane at a given distance from the radiating aperture. The position and size of the slots of the RLSA antenna are automatically controlled to synthesize the derived aperture field distribution. The design approach is validated by measurements at $12.5 \mathrm{GHz}$.
\end{abstract}

\section{INTRODUCTION}

RLSA antennas are well-known antenna solutions for farfield applications. Their main features are high efficiency, planarity, and compactness [1]-[3]. The possibility to automatically design and optimize such antennas has recently provided new directions for performance enhancement [3]. The efficiency, simplicity and automatic design of RLSA structures make such antennas extremely attractive for near field applications as near-field probing, radiometry, non-invasive medical imaging, etc. [4]-[6].

Here we propose the design of a RLSA antenna focusing the normal component of the electric field in the near field with reduced side lobe levels and defined beamwidth. The design methodology is divided in two main steps. In the first step, the required near-field pattern is defined over a certain plane parallel to the RLSA aperture. The aperture field distribution generating such near-field pattern is then derived based on a set theoretic approach and alternate projection method [7]. In the second step, the derived aperture distribution is synthesized on the RLSA aperture by properly tuning the positions and sizes of the slots of the RLSA. The automatic design procedure proposed in [3] is extended to the near field and linked to an in-house Method of Moment (MoM) [8] to speed up the computational time and optimization process.

\section{DESIGN PROCEDURE}

The geometry of the problem is shown in Fig. 1. An aperture of size $S_{A}$ is located at $z=0$ and is radiating in free space. The required pattern is defined over a focusing plane $\left(S_{F}\right)$ located at a distance $z=h$ and parallel to the radiating aperture. Transverse magnetic (TM) modes with respect to the $z$-direction and with $\phi$ invariance are considered. In the present case, the requirements on the near field are expressed on the normal component of the electric field $\left(E_{z}\right)$ in the focusing plane $\left(S_{F}\right)$ providing a mask for the near field as:

$$
\text { Mask }= \begin{cases}\frac{\left|E_{z}(x, y, h)\right|}{\max \left(\left|E_{z}(x, y, h)\right|\right)}>c_{1} & \text { in } A_{1}, \\ \frac{\left|E_{z}(x, y, h)\right|}{\max \left(\left|E_{z}(x, y, h)\right|\right)}<c_{2} & \text { in } A_{2},\end{cases}
$$

where $0<c_{2}<c_{1}<1$ are fixed limits for the normalized module of $E_{z}$ in some space domains $A_{1}$ and $A_{2}$ over the focusing plane, respectively and $\max \left(\left|E_{z}\right|\right)$ indicates the maximum value of the $z$-component of the electric field. A set theoretic approach and alternate projection method [7] are then used to derive the aperture field distribution that generates the required pattern. A Fast Fourier Transform (FFT) algorithm is adopted to evaluate the fields at the focusing $\left(S_{F}\right)$ and aperture plane $\left(S_{A}\right)$. In addition, at each step $(n)$ of the iterative procedure only the module of the electric field is modified for the next step $(n+1)$ accordingly to the defined mask as:

$\left|E_{z}^{(n+1)}(x, y, h)\right|=\left\{\begin{array}{l}\max \left(\left|E_{z}^{(n)}\right|\right) c_{1} \text { if } \frac{\left|E_{z}^{(n)}\right|}{\max \left(\left|E_{z}^{(n)}\right|\right)}<c_{1} \text { in } A_{1}, \\ \max \left(\left|E_{z}^{(n)}\right|\right) c_{2} \text { if } \frac{\left|E_{z}^{(n)}\right|}{\max \left(\left|E_{z}^{(n)}\right|\right)}>c_{2} \text { in } A_{2} .\end{array}\right.$

The procedure is repeated until $E_{z}$ lays within the imposed requirements in the focusing plane or the error with respect to the defined mask is lower than a certain threshold.

For the second step of the design procedure, the tangential aperture field distribution is required to synthesize the RLSA structure. This distribution is evaluated from the normal component of the electric field following similar steps of those proposed in [6]. The position and size of the slots of the RLSA antenna are then automatically optimized by using an automatic design procedure as in [3].

\section{PRototype AND EXPERIMENTAL Results}

A RLSA antenna has been designed with a shaped $z$ component of the electric field $\left(E_{z}\right)$. The operating frequency is equal to $f_{0}=12.5 \mathrm{GHz}$. The focusing plane is placed at a distance equal to half the antenna size $(h=150 \mathrm{~mm})$. The following mask is imposed on the normalized $E_{z}$ profile over the focusing plane:

$$
\text { Mask }= \begin{cases}\frac{\left|E_{z}\right|}{\max \left(\left|E_{z}\right|\right)}>-3 \mathrm{~dB} & \text { for } \rho<10 \mathrm{~mm}, \\ \frac{\left|E_{z}\right|}{\max \left(\left|E_{z}\right|\right)}<-14 \mathrm{~dB} & \text { for } \rho>20 \mathrm{~mm} .\end{cases}
$$




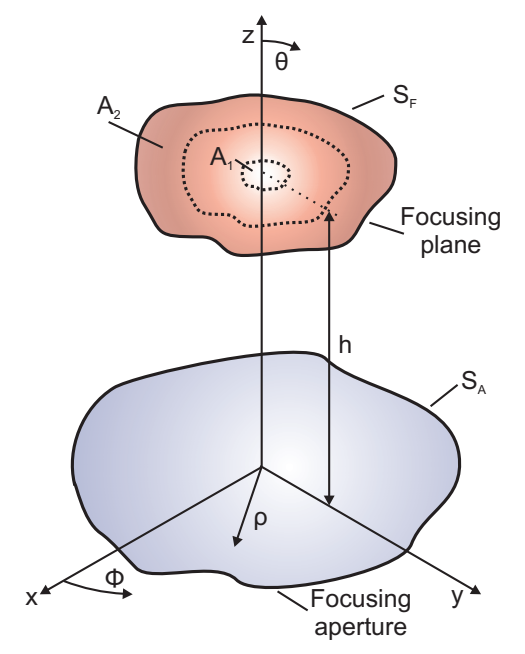

Fig. 1. Geometry of the problem with two generic surfaces defined on two parallel planes orthogonal to the $z$-axis. The focusing aperture $S_{A}$ is located at $z=0$. The focusing plane $S_{F}$ is at $z=h$.

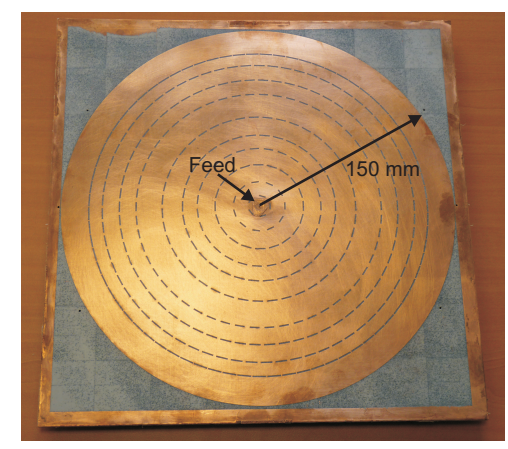

Fig. 2. Final prototype. The slots have been etched by laser ablation.

A prototype has been manufactured and tested at IETR and is shown in Fig. 2] The slots of the RLSA are etched on the upper face of a double grounded Neltec NY9217 substrate with permittivity 2.17 and height $3.175 \mathrm{~mm}$. The prototype is centrally fed by a coaxial probe attached on the back side of the prototype to a SMA connector.

The $E_{z}$ component of the electric field was measured above the prototype using a short electric probe attached to an automatically controlled $2 \mathrm{D}$ translation stage. The normalized $E_{z}$ component at the operating frequency $f_{0}$ along the $x$ - and $y$-axis is shown in Fig. 3 (a) and (b), respectively. 2D plots of the fields are also provided in Fig. 3 (c) and (d). Good agreement is achieved between the measured and simulated results [8]. A good circular symmetry of the pattern can be also appreciated.

\section{CONCLUSION}

The design and measurement results for a RLSA antenna focusing in the near field have been presented. The possibility to control the side lobe level and beamwidth of the vertical component of the electric field has been considered. The RLSA structure is automatically generated by a novel

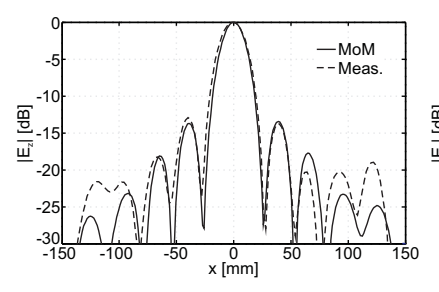

(a)

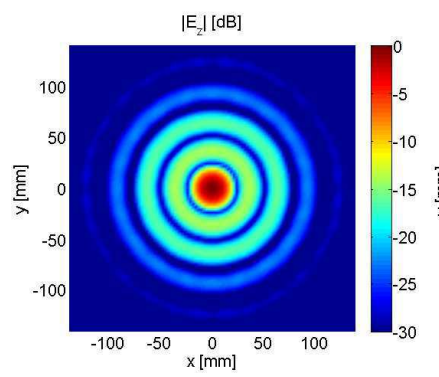

(c)

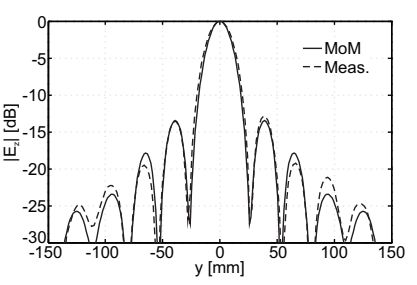

(b)

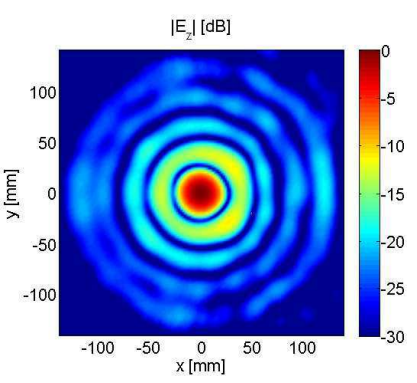

(d)
Fig. 3. Normalized $E_{z}$ component of the electric field at $f_{0}$ on the focusing plane. (a) Comparison between measured and MoM results along the $x$-axis. (b) Comparison between measured and MoM results along the $y$-axis. (c) 2D MoM electric field plot. (d) 2D measured electric field plot.

design procedure using as inputs the requirements on the near field. 2D measurements validated the proposed approach and realized prototype. The proposed structure and design technique may find application in areas such as radiometry, wireless power transfer, and medical imaging.

\section{ACKNOWLEDGEMENT}

The authors would like to thank Rennes Métropole (AIS project) and Campus France-Universitá Italo Francese (Galileo project) for their support.

\section{REFERENCES}

[1] N. Goto and M. Yamamoto, "Circularly polarized radial-line slot antennas," IECE Japan, Tech. Rep., APSO-57, Aug. 1980.

[2] M. Ando, K. Sakurai, N. Goto, K. Arimura, and Y. Ito, "A radial line slot antenna for $12 \mathrm{GHz}$ satellite TV reception," IEEE Trans. Antennas Propag., vol. 33, no. 12, pp. 1347-1353, Dec. 1985.

[3] M. Albani, A. Mazzinghi, and A. Freni, "Automatic design of CP-RLSA antennas," IEEE Trans. Antennas Propag., vol. 60, no. 12, pp. 55385547, Dec. 2012.

[4] M. Bogosanovic and A. G. Williamson, "Microstrip antenna array with a beam focused in the near-field zone for application in noncontact microwave industrial inspection," IEEE Trans. Instrum. Meas., vol. 56, no. 6, pp. 2186-2195, Dec. 2007.

[5] K. D. Stephan, J. B. Mead, D. M. Pozar, L. Wang, and J. A. Pearce, "A near field focused microstrip array for a radiometric temperature sensor," IEEE Trans. Antennas Propag., vol. 55, no. 4, pp. 1199-1203, Apr. 2007.

[6] M. Ettorre and A. Grbic, "Generation of propagating Bessel beams using leaky-wave modes," IEEE Trans. Antennas Propag., vol. 60, no. 8, pp. 3605-3605, Aug. 2012.

[7] R. Piestun and J. Shamir, "Synthesis of three-dimensional light fields and applications," Proc. IEEE, vol. 90, no. 2, pp. 222-244, Feb. 2002.

[8] M. Casaletti, G. Valerio, J. Seljan, M. Ettorre, and R. Sauleau, "A full-wave hybrid method for the analysis of multilayered SIW-based antennas," IEEE Trans. Antennas Propag., vol. 61, no. 11, pp. 55755588, Nov. 2013. 